\title{
The Pakaru 'Pipeline': Māori and Pasifika Pathways within the Academy
}

\author{
Sereana Naepi ${ }^{a}$, Tara G. McAllistera , Patrick Thomsen, Marcia Leenen-Younga, \\ Leilani A. Walker ${ }^{a}$, Anna L. McAllister, Reremoana Theodore ${ }^{b}$, Joanna Kidmanc, \& \\ Tamasailau Suaalii ${ }^{a}$ \\ a University of Auckland \\ ${ }^{b}$ University of Otago \\ ${ }^{c}$ Victoria University Wellington
}

We examine the academic 'pipeline' for Māori and Pasifika graduates and illustrate the chronic underrepresentation of Māori and Pasifika in permanent academic positions in New Zealand universities. We identify areas within higher education where significant opportunities are being lost for the recruitment and retention of Māori and Pasifika. The narratives of Māori and Pasifika post-doctoral researchers, research associates and professional teaching fellows provide further insight into the advantages and disadvantages of these positions. Lastly, we propose a Pacific alternative metaphor 'Pacific Navigation of Academic Pathways' based on Pacific navigation, as opposed to the more commonly used term 'pipeline', in order to capture the nuances of Pasifika and Māori experiences.

Keywords: Māori, Pasifika, Pacific, university, pathways

\section{Introduction}

In higher education, the term 'academic pipeline' is often used in debates about academic equity and representation to show how minority students are 'leaking' out of academic career progression from undergraduate to professor, with the core assumption being that this progression is linear (Fradella, 2018; Sethna, 2011; Van Anders, 2004; Ysseldyk et al., 2019; Zusi, 2016). Pipelines traditionally identify areas where these leaks occur and suggest ways in which they can be fixed (Fradella, 2018; Sethna, 2011; Van Anders, 2004; Ysseldyk et al. 2019; Zusi, 2016). Solutions to the 'leaky pipeline' have included, for example, the need to "create postdoctoral fellowships to recruit and train people from underrepresented groups for potential tenure-track faculty positions" (Fradella, 2018, p. 139). Post-doctoral fellowships provide emerging academics with the opportunity to publish, apply for research grants and develop their own research agenda, which contributes to their professional development and competitiveness in the job market. There are critiques of the pipeline metaphor both internationally and nationally (Fradella, 2018; Pihama et al., 2018). Internationally, the pipeline metaphor has been critiqued for failing to address why racialised academics are not more aggressively recruited; 
instead, the pipeline centres individual progression as opposed to systemic failure (Fradella, 2018). Nationally, it has been argued that the pipeline does not reflect the many divergent paths that emerging Māori scholars can and do take, nor does it reflect the systematic barriers Māori and Pasifika experience within academic institutions (Kidman \& Chu, 2017; Pihama et al., 2018).

This paper makes three arguments that build upon previous work critiquing notions of a 'leaky pipeline': 1) the pipeline for Māori and Pasifika is fundamentally pakaru (broken) if we consider quantitative data from New Zealand universities that show the under-representation of Māori and Pasifika staff in both precarious (e.g., fixed term contracts) and permanent positions (e.g., lecturers); 2) the pipeline metaphor is not appropriate for understanding Māori and Pasifika journeys in permanent academic positions; and 3) there need to be more opportunities for Māori and Pasifika academic development through post-doctoral fellowships, research associates, and professional teaching fellowships. In order to make these arguments, we outline New Zealand university contexts, including how current commitments (such as those outlined by Universities New Zealand, 2019) to Māori and Pasifika are not being fulfilled. We describe the impact of neoliberal education policies and practices within universities, and note the urgency of developing pathways for Māori and Pasifika entering the academic job market. Following this, we provide findings on current numbers of students and academic staff ranging from undergraduate through to professors/deans across different institutions. We then provide narratives that explore the different pathways into permanent academic positions taken by emerging Māori and Pasifika scholars and suggest an alternative model (Pacific Navigation of Academic Pathways) to the pipeline metaphor using the example of Pacific people's journeys into academic positions. Finally, this paper discusses the impact of these findings and suggests some ways forward for universities and the government to support Māori and Pasifika pathways to permanent academic positions.

\section{Definitions}

Māori are the Indigenous people of Aotearoa New Zealand. Our use of Pasifika refers to people of Pacific ancestry (excluding Māori) who reside in Aotearoa. The majority of Pasifika living in Aotearoa were born in Aotearoa and therefore are not an immigrant population. Historically, Pacific people participated in four waves of migration, the most important being the first wave of discovery and settlement when Pacific people, having explored the largest ocean on the planet, came from the east, intentionally navigating southwards to discover Aotearoa (Finney, et al., 2007; Mallon, Māhina-Tuai, \& Salesa, 2012). Those who remained became tangata whenua (local/indigenous people). This first wave is the most significant for understanding the relationship of Pasifika to Māori as it cemented Pasifika as extended family to Māori and created bonds and relationships through culture and genealogy in Te Moana Nui ā Kiwa (greater Oceania kinship connections) (Health Research Council, 2014). Our use of 'Pacific' refers to Māori, Pasifika and regional Pacific peoples. It acknowledges our shared whakapapa and that we see this as an opportunity to move forward together.

When we use the term 'New Zealand universities' we are referring to crown-owned universities including Auckland University of Technology, Lincoln University, Massey University, University of Auckland, University of Canterbury, University of Otago, University of Waikato and 
Victoria University of Wellington. These universities have shared funding models, histories and ontological foundations.

'Pathways' in this paper refer to the different steps that emerging academics can take in order to achieve a permanent academic job. These pathways include temporary, part-time or full-time positions. For example, post-doctoral fellowships where a candidate has a doctorate and the position is defined (i.e., advertised with a specific research goal in mind and usually connected to an established project), or undefined (i.e., advertised and open for the candidate to set their own research agenda). Pathways also include research associates (where the position is tagged to a specific research goal, is usually connected to an established project, and the candidate may or may not have completed their doctorate) and professional teaching fellows (PTF) (where the position is dedicated to teaching and the candidate does not need a doctorate).

\section{Context}

\section{Diversity and Inclusion in New Zealand universities}

Māori and Pasifika have traditionally been and are currently under-represented and excluded from universities in New Zealand. McAllister et al.'s (2019) and Naepi's (2019b) research on the current numbers of Māori and Pasifika academics show that there is a pressing need to recruit, retain, and promote Māori and Pasifika academics as they remain severely under-represented despite commitments from government and universities to serve Māori and Pasifika communities better. McAllister et al. (2019) explored how current university commitments to Te Tiriti o Waitangi and Māori have not resulted in significant increases in Māori academic employment. Naepi (2019b) showed evidence of the foundational whiteness of universities and associated practices and policies through the exclusion and under-representation of Pasifika academics. Relevant to both Māori and Pasifika are universities' practices of reproducing a colonial and monocultural knowledge system firmly anchored in Western understandings of the world which can devalue Māori and Pasifika knowledge (Kidman \& Chu, 2019; Māhina, 2008; Naepi, 2019a; Suaalii-Sauni, 2008; Thaman, 2003). This may contribute to the slow progression of Māori and Pasifika through to senior roles and the exclusion of Māori and Pasifika bodies from universities.

\section{Neoliberalism}

Outside of universities' lacklustre performance within the public sector to Te Tiriti o Waitangi, diversity and inclusion policies and institutional practices (McAllister et al., 2019; Naepi, 2019b), there is a wider system that may contribute to universities failing to fulfil their diversity policies. New Zealand universities began the neo-liberalisation process in the 1980 s at a time of nation-wide economic restructuring (Murray, Bebam, \& Walters, 2018; Roper, 2018). This involved a shift towards a corporate market-driven logic that saw education "as an input-output system which can be reduced to an economic production function" (Olssen \& Peters, 2005, p. 324). Over time, these economic practices created an environment in New Zealand universities where redundancies, early retirement and a growth in the 'precariat' (academic and administrative staff who are employed on fixed or short-term contracts) characterised the workforce (Murray et al., 2018; Stringer, Smith, 
Spronken-Smith, \& WIlson, 2018). In these environments Māori and Pasifika knowledge may be valued if it is commodifiable or marketable, with less employment stability or precarious employment for Māori and Pasifika.

The shortage of permanent positions and increase in eligible candidates (Education Counts, 2017) makes it increasingly urgent to provide Māori and Pasifika doctoral graduates with pathways into permanent academic positions and leadership roles. McAllister et al. (2019) and Naepi (2019b) show there was growth in academic positions between 2012 and 2017 in universities but the majority of them (1070 out of 1575) were defined as "other academic staff/tutorial assistants'" academic levels. This suggests that these positions were temporary contracts, which mirrors current international trends of expanding the pool of casual academic labour (Childress, 2019). In order to ensure that Māori and Pasifika do not continue to be overrepresented in casual positions (e.g., McAllister et al., 2019; Naepi, 2019b), institutions need to create opportunities that enable Māori and Pasifika doctoral graduates to gain experience in research, drafting funding applications and knowledge dissemination more broadly so that when a rare permanent entry level academic position arises, they have the experience necessary to be successful in their application.

\section{Funding}

There are a number of ways in which universities could access or leverage research funding to create Māori and Pasifika pathway positions. In 2015, universities spent $\$ 877$ million on research from both external and government grants (Education Counts, 2017). The Tertiary Education Commission (TEC) provides research funding to universities as a part of their commitment to "Increasing research quality and capability" (TEC, 2019a, p. 11). Part of the function of the Performance Based Research Fund (PBRF) is to support "the development of postgraduate student researchers and new and emerging researchers" (TEC, 2019a). In order to do this, the PBRF provides $\$ 315$ million in funding to universities (TEC, 2019b) of which $25 \%$ is meant to reflect the number of postgraduate degrees awarded and includes an equity weighting of 2 for Māori and Pasifika student completions and 1 for all other ethnicities (TEC, 2016). This differential weighting highlights the PBRF's commitment to Māori and Pasifika advancement and is used to incentivise universities to support Māori and Pasifika student completions. In 2016, universities received a total of $\$ 72.61$ million in research degree completion from PBRF (Education Counts, 2017). To date there is little to no public information regarding how universities spend their allocated \$72.61 million funding that they have received as a direct result of emerging researchers completing their degrees.

\section{Methods}

Data reported by universities to the Ministry of Education (MoE) were acquired through the Education Counts website (www.educationcounts.govt.nz; see McAllister, 2019; Naepi, 2019b for further detail). Ethnicity data are split into the following groups: European, Māori, Pasifika, Asian and Other. 'Other' includes the categories, 'Not Further Defined', 'Middle Eastern', 'Latin American', 'African' and 'other ethnicities'. Staff and students may select more than one ethnicity. We present data and percentages for Māori, Pasifika, Pākehā (reported as European) 
and non-Māori/Pasifika. The latter group includes all staff and students of unknown ethnicity, Asian and Other.

Data on undergraduates, Masters and PhD students represent the number of students enrolled at any time of the year in New Zealand universities in 2017. Post-doctoral fellows include research fellows and data on post-doctoral fellows and the other academic positions reported to the MoE based on the full calendar year of 2017. Data presented in Naepi (2019b) and McAllister et al. (2019) included the academic category of "Other academics/tutorial assistants"; however, for the purpose of examining Māori and Pasifika academic pathways we have excluded this group as we cannot confirm what roles the different universities include in the 'other academic' classification and we wished to ensure that the data reflected pathway positions. Data on the number of PhD enrolments across all universities by ethnicity were acquired from 1994 to 2018. Raw data could not be obtained and all data were rounded up to the nearest five people due to privacy concerns. Therefore, the data presented in this paper could overestimate the exact numbers of Māori and Pasifika in universities.

Māori and Pasifika co-authors of this paper who were also early career researchers employed in post-doctoral fellowships, professional teaching fellows and research associate positions were invited to contribute to this paper and share their stories, experiences and pathways within academia (qualitative results). We gathered these stories through written talanoa (Naepi et al., 2017), each of us sharing what we believed was important to a discussion on the 'pipeline' and our experiences of it. In order to add context and nuance to our quantitative analyses, we identified key and recurring themes from these stories that have been grounded in existing literature.

\section{Quantitative results}

\section{The Māori and Pasifika Pipeline}

The overall pipeline of Māori and Pasifika undergraduate students to professors/deans illustrates a dramatic decrease in numbers as the level of academic seniority rises (Figure 1). The ratio of undergraduate students to professors/deans differs according to ethnicity. The ratio is lowest for Pākehā (1:95) and highest for Pasifika with one Pasifika professor/dean to 1829 Pasifika undergraduate students (Figure 1).

Our data show there are very few Māori and almost no Pasifika professors/deans (Figure 2) and that the majority of New Zealand university academics are non-Māori and non-Pasifika, with ethnic inequalities increasing as levels of academic seniority increase (i.e., associate professor/HOD and professor/dean; Figure 1, Figure 2). In 2017, the University of Auckland and the University of Otago were the only universities that reported having Māori representation at all academic levels (Figure 2).

There were very few Māori (55) and Pasifika (20) post-doctoral fellows employed in universities in 2017, according to MoE data (Figure 2). Lincoln University, which is the smallest university, was the only university that did not follow the trend of attenuation with increased level of seniority with a high percentage of professor/deans with little to no Pasifika at lower levels. They are also the only university that reported having a Pasifika professor/dean (Figure 1). 


\section{The raw numbers}

The number of Māori PhD students enrolled in 2017 was much higher than the number of Māori academic staff employed at all levels within the academy (Figure 1, Figure 2). The total number of Māori enrolled in PhDs has increased markedly from 75 in 1994 to 630 in 2018 (Figure 3). There has also been an increase in the number of Pasifika enrolled in PhDs, from 15 in 1994 to 290 in 2018 (Figure 3). Five universities (Auckland University of Technology, the University of Auckland, the University of Otago, Victoria University of Wellington, University of Canterbury) reported having Māori post-doctoral fellows in 2017 (Figure 1). However, at two of these institutions, numbers were fewer than 5. Similarly, only the University of Auckland, Auckland University of Technology, Victoria University of Wellington and the University of Otago recorded having Pasifika post-doctoral fellows in 2017 (Figure 1).

The overall number of Pasifika PhD students enrolled in 2017 is much higher than the number of Pasifika academic staff employed at all levels within the academy (Figure 2). The number of Pasifika academics is much more sporadic, compared to Māori, across institutions (Figure 2). With the exception of the University of Auckland, there appears to be no continuity in the number of Pasifika academics as roles progress up the academic rankings (Figure 1). Excluding Auckland University of Technology and the University of Auckland, there were approximately 45 Pasifika academics employed in 2017 across all academic levels. There was an absence of Pasifika academic representation at the Associate professor/HOD and professor/dean levels in 2017 (Figure 1, Figure 2). There was Pasifika representation from PhD to associate professor/HOD at only one university, the University of Auckland.

\section{MĀORI}
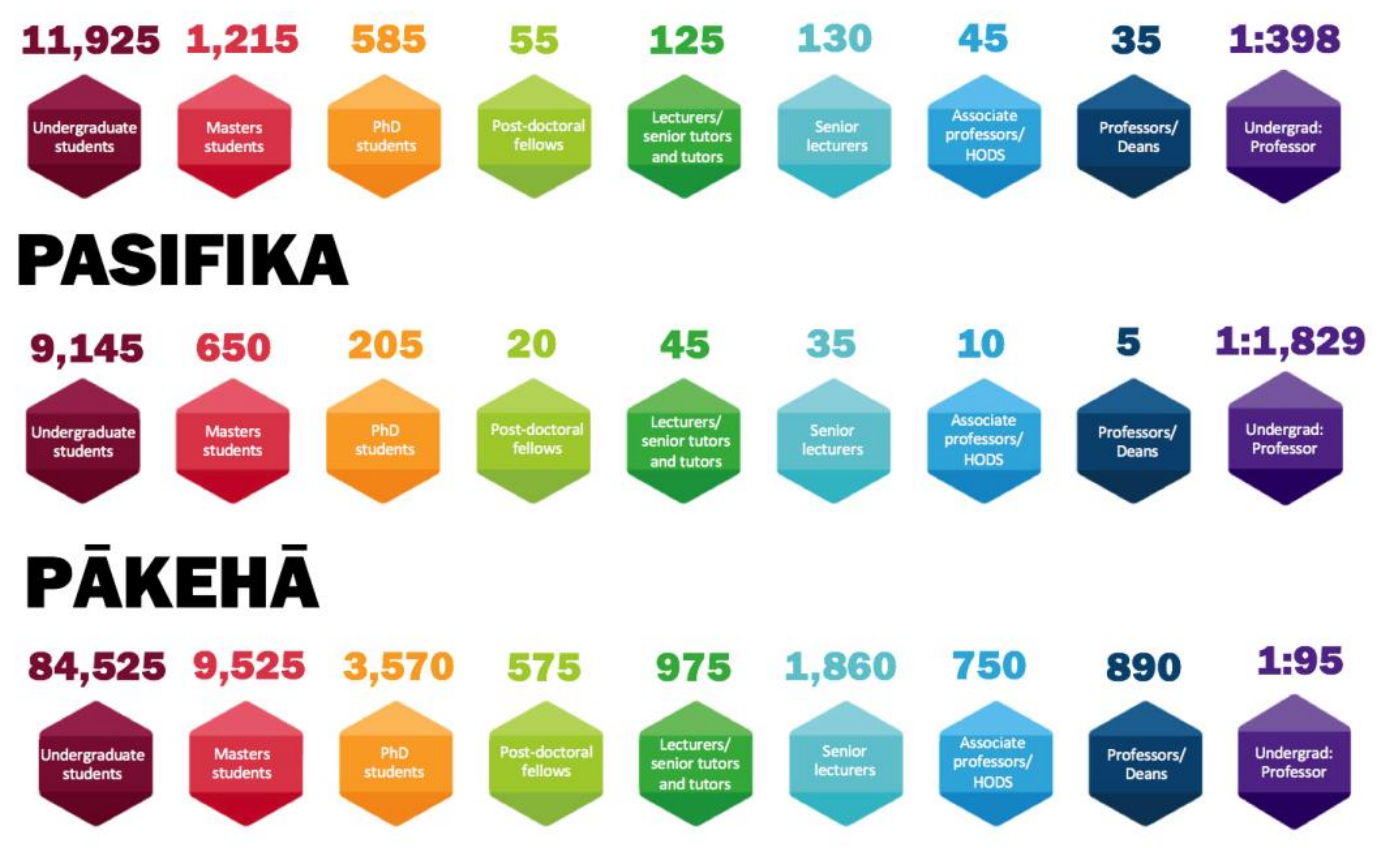

Figure 1. The total number of Māori, Pasifika and Pākehā students enrolled and research (post-docs) and academic staff employed at all universities in 2017. All numbers were rounded up to the nearest five by the MoE 

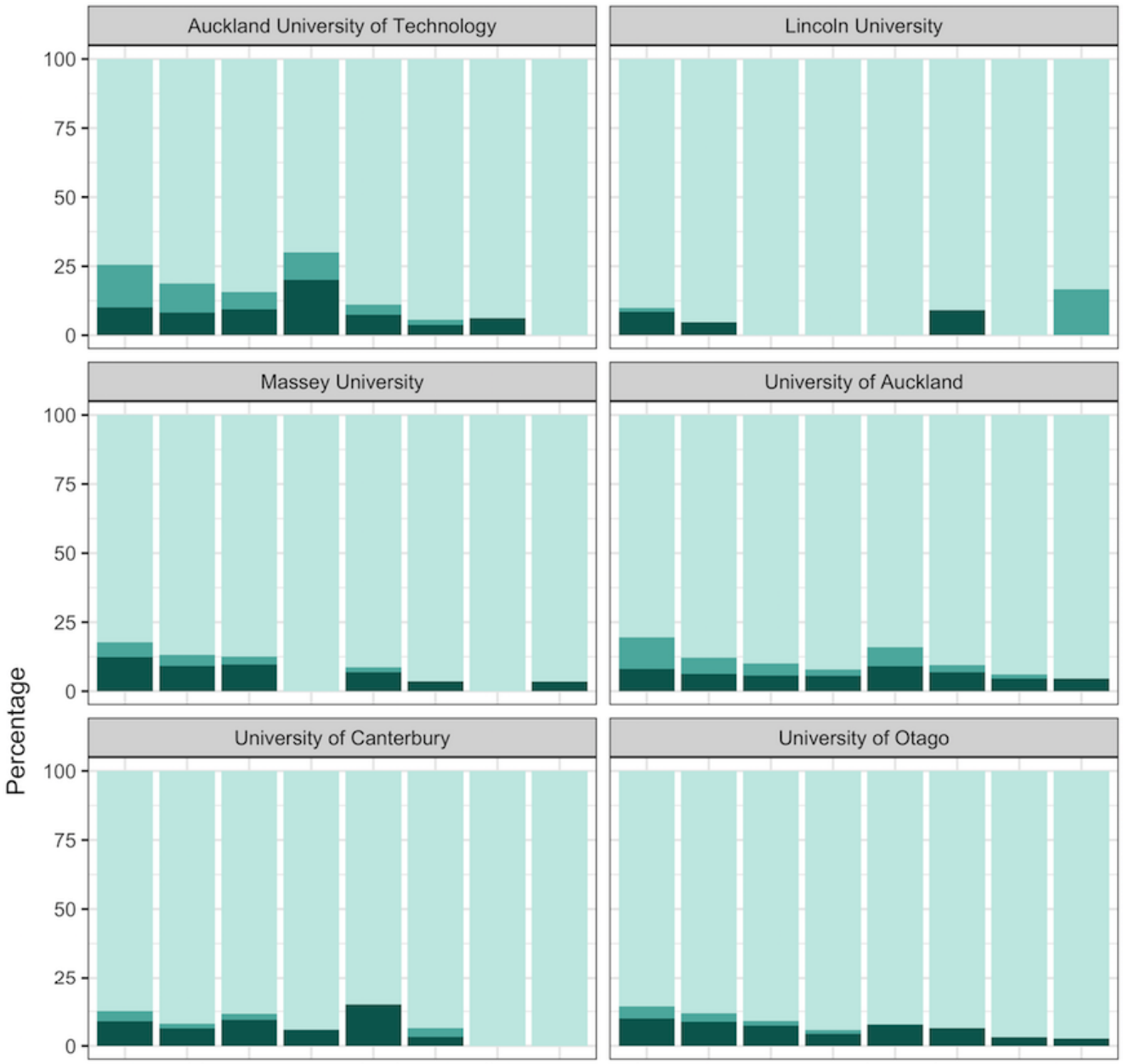

Ethnicity

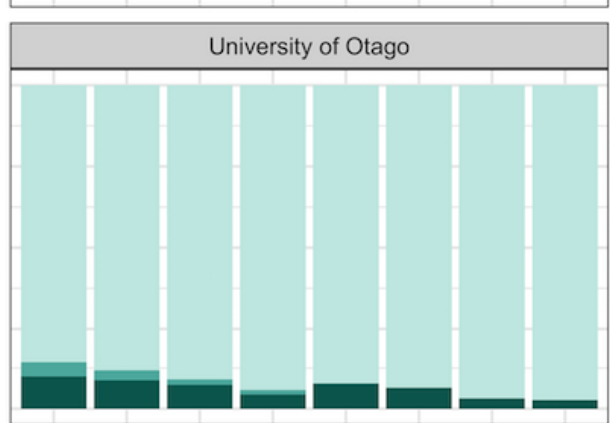

\begin{tabular}{l} 
non-Māori/Pasifika \\
Pasifika \\
\hline Māori
\end{tabular}
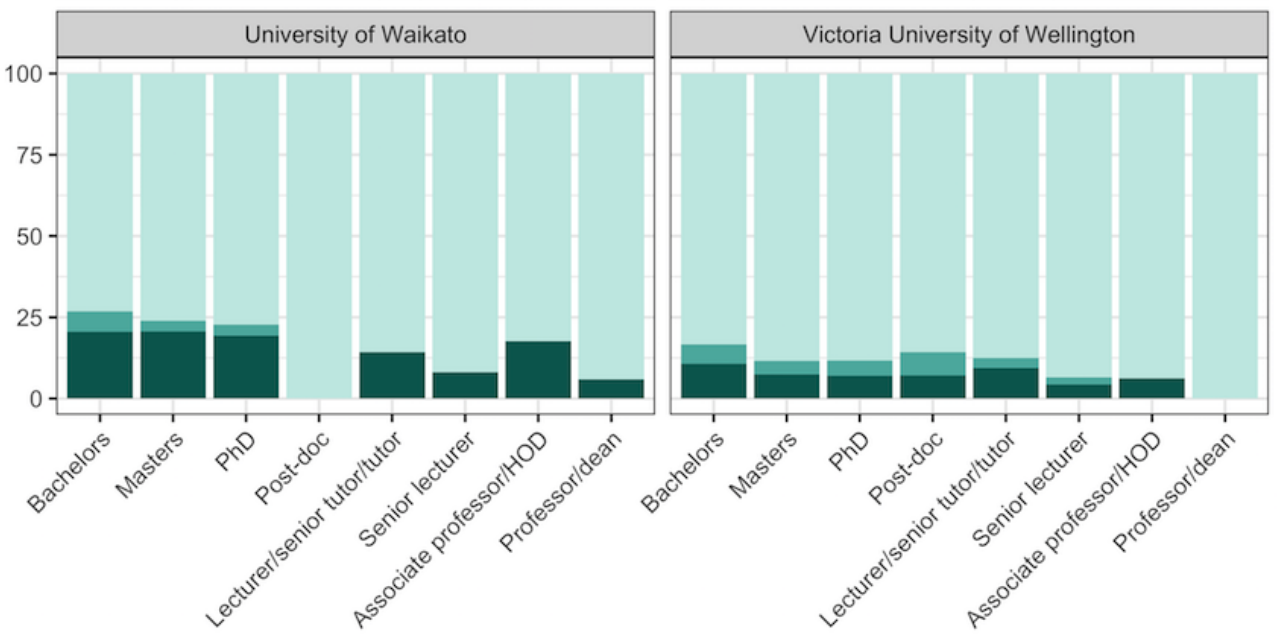

Academic level

Figure 2. The percentage of Māori and Pasifika students enrolled and research (post-docs) and academic staff employed by each university in 2017. All numbers were rounded up to the nearest five by the MoE before we converted them to percentages 


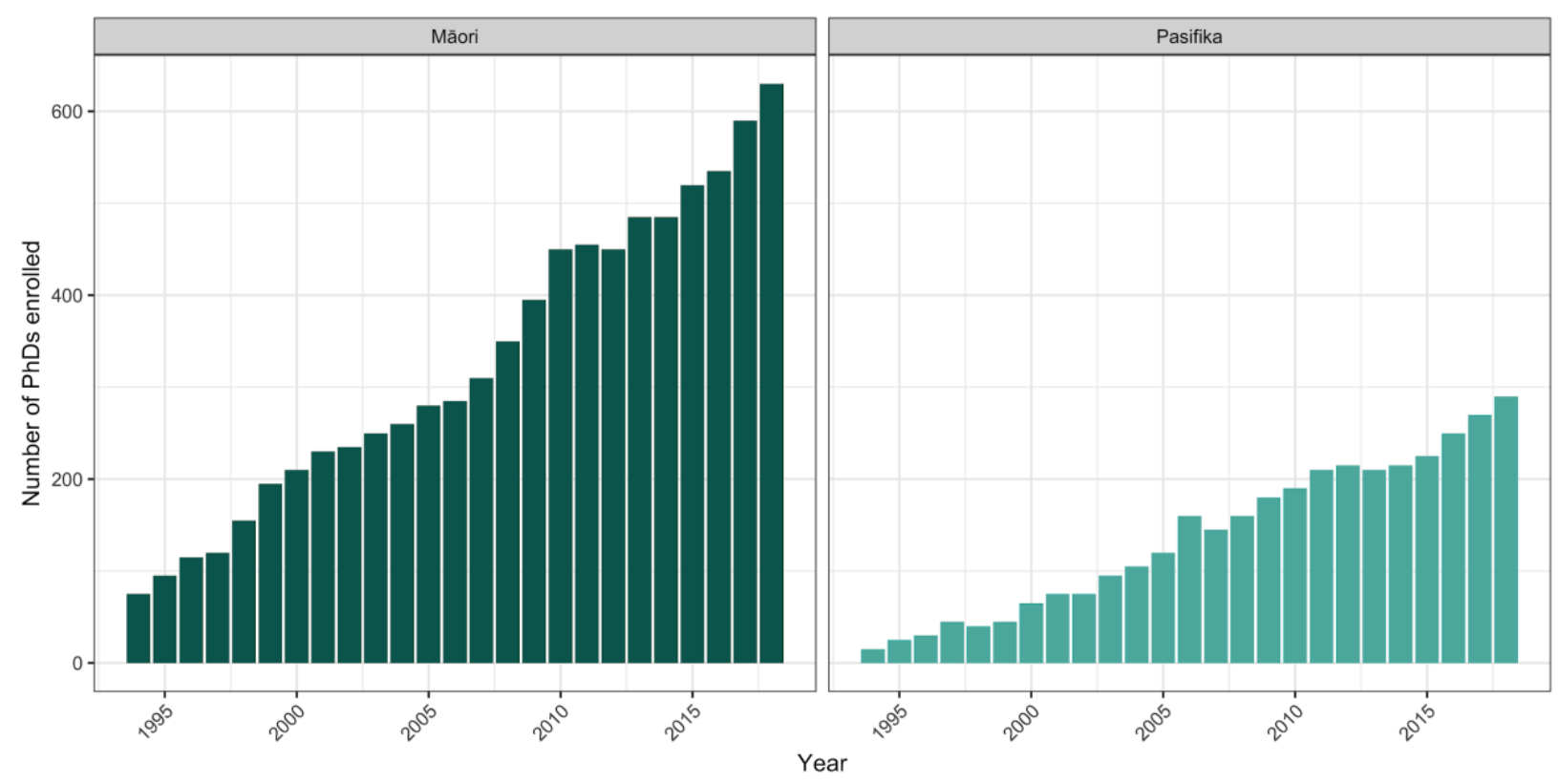

Figure 3. The total number of Māori and Pasifika PhD students enrolled in New Zealand Universities from 1994 to 2015 . All numbers were rounded up to the nearest five by the Ministry of Education (MoE)

\section{Qualitative results - Emerging academic narratives}

In addition to the numbers, it is important to tell our stories as emerging Māori and Pasifika academics. These experiences reinforce much of the literature of racialised bodies within universities and also highlight issues specific to Māori and Pasifika in universities in Aotearoa. Below is a thematic analysis of our written talanoa outlining our experiences as post-docs, professional teaching fellows, and research associates.

\section{Excess Labour}

Previous authors have argued that those who labour within neoliberal higher education institutions without the privileges accorded to upper-middle class male academics are faced with overwhelming and unreasonable demands to the point where those who engage in the system become unwell (Mountz et al., 2015) or their work is simply not valued (Kandiko Howson, Coate, \& de St Croix, 2017; Morley, 2005; White, Carvalho, \& Riordan, 2011). Naepi (2018) argues that excess labour contributes to Pasifika females not meeting other expectations of performance, which hinders their career progression, whilst other bodies progress off the back of Pasifika women's excess labour. Our stories of progressing through the academy show that this pattern of excess labour begins early for Māori and Pasifika academics.

This landscape is further complicated by the knowledge that Māori academics are often used to tick boxes on proposals by academics who, consciously or not, do not have our personal career aspirations in mind. "Having to adapt to doing the "Māori part" of projects is stressful because it can put our cultural integrity at risk and the teams we enter sometimes do not have 
another social scientist or Māori person on the team. In these situations, we will frequently take the initiative in making sure that protocols are followed; this is not explicitly our responsibility but Pākehā scientists do not know what they do not know, and in the interests of project cultural safety, it often falls to us to keep an eye out and make sure that things go smoothly. We could just let things play out on their own but, in the interests of the people and work involved, and our own careers, we have an added responsibility to our communities to do [it] in a tika (correct) way:

In addition, the fact that we must dedicate much time to equity projects is a type of labour our White colleagues do not have to necessarily engage in. The lack of Pasifika academics has also meant that along with many colleagues, we are often called upon to diversify curriculums in different schools and take-up a disproportionately higher share of service roles as Pacific representatives. Although this provides us with great opportunities for collaboration and extending networks across the university, often the option to opt-out does not exist. For if we do not take up the task of equity, who else will?

The reflections above reinforce that from early in our careers we are being asked to engage in excess labour which can impact on us being able to undertake our own research and teaching and is not always valued by the university in ways that will enable our careers to progress.

\section{Precarity}

It has become more common for emerging researchers to describe feelings of precarity and a strong critique of universities' reliance on an academic precariat (Murray et al., 2018; Stringer et al., 2018). Our stories highlight that this is also the case for Māori and Pasifika and concur with findings from McAllister et al. (2019) and Naepi (2019b) who showed that Māori and Pasifika are over-represented within temporary contracts in New Zealand universities:

This also places me in a blurry space. As a post-doc there is no guarantee of permanent employment, which makes the way I navigate all these complexities even more important. You must be "seen" as a valuable asset to the institution or they may find no reason to keep you on. Thus, the calculation around what you say yes and no to can be fraught with difficulties as you weigh up your agency versus the needs of the institution.

But we feel a strong sense of vulnerability because we may not be so lucky on the next contract.

We also face the usual challenges of post-doctoral life: the expectation that we will have to complete several fixed term post-docs before being competitive for permanent employment; increasing domestic responsibilities and costs; and the spectre of having to relocate for work.

When faced with the precarious nature of the post-PhD period, it seems risky to turn down career opportunities but it becomes clear in various conversations that you are not being valued for your skills as a researcher but as a Māori person to tick a box with. 
I have had three separate contracts with three different faculties within the same university ranging from 6 months to 2 years. They are technically academic positions, but do not allocate time for research and so have a very heavy teaching expectation. I sacrificed permanent employment in order to take this leap and went from PTF position to PTF position trying to find opportunities to develop my skills. Although there was anxiety with the lack of job security it was a conscious decision in order to have a foot in the door with an academic position, but this was only possible because I had the security of my family and no children to provide for - this is not a path that would appeal to everyone.

Our narratives demonstrate that the precarity of our positions is explicitly linked to excess labour; our concern that the one time we turn down an invitation to do service as Māori or Pasifika will be the thing that is remembered when it comes to contract renewal or permanent hiring. All of us indicated a feeling of uncertainty in relation to our pathway positions, unsure how long we would work from contract to contract.

\section{Developing key skills}

Post-doctoral positions have long been recognised as being valuable stepping stones into research careers (Horta, 2009), and our stories reflect this and also that other pathway positions have been valuable in establishing some key skills needed in the academic job market. However, for some of the pathway positions (e.g., professional teaching fellows), extra labour is needed to be undertaken in order to build up an academic portfolio that includes research outputs:

...helped me develop strong teaching skills, but this is only one aspect needed to be marketable for a permanent academic position.

However, the key component missing from this role in order to achieve a permanent academic position was the development of a research portfolio. I managed to get an internal research fellowship that was focused on Pacific student achievement, and this in many ways pushed me over that barrier by giving me research experience, demonstrated my ability to attract funding, and increased my specialisation on Pacific pedagogy. This, on top of my teaching experience, added to my ability to gain a permanent position on the academic 'pipeline'. My time in my pathway position helped me make that parallel jump onto the 'pipeline'; however, it did not arm me with the necessary experience to progress smoothly up the academic pathway; that is a matter of learning on the job.

I haven't had the post-doc title (and the prestige that comes with it) but I have had the opportunity to be a co-applicant on multi-million dollar grants, run research development programs, teach graduate courses, work on province wide government education initiatives, coordinate national gatherings, coordinate large research projects, establish a research centre and publish in both my own field and the field of those I report to. As a whole it has been a moment that has enabled me to build an understanding of how universities and research funding work, establish important networks and take some time to plan out the next steps in my career. Unlike a post-doc my own research has not been a priority which means my PhD work is still unpublished which is uncommon and made me anxious about finding work in my field. 
Our experiences highlight that pathway positions are valuable for establishing and developing key skills needed within the academic workforce. They provide important opportunities to learn about research, funding applications, publications, and teaching which can later be used to secure permanent positions in a highly competitive workforce.

\section{Discussion}

\section{Quantitative}

In 2017, there were many more Māori and Pasifika students (undergraduate, masters and PhDs) than academic staff. Further, the numbers of Māori and Pasifika enrolled in PhDs have continued to increase substantially over two decades, providing evidence that Māori and Pasifika underrepresentation in New Zealand universities is not due to a lack of available talent. We argue that institutional barriers (including racism, neoliberalism, PBRF-driven hiring) and a lack of available positions are more influential than the lack of available academic talent (McAllister et al., 2019; Naepi, 2019b). Despite the small numbers, the data suggest that there is academic representation from PhD to professor/dean for Māori at most universities (with the exception of Lincoln University). Comparatively, the academic 'pipeline' for Pasifika scholars, based on current data, appears to be non-existent. In 2017, only the University of Auckland showed a clear progression for Pasifika academics. The University of Auckland had Pasifika representation throughout the system (apart from at the professor/dean level). According to MoE data, there appear to be key universities for training the next generation of Pasifika scholars, including Auckland University of Technology, the University of Auckland, and Victoria University of Wellington, that had more than 20 Pasifika PhDs enrolled in 2017. Alarmingly, the University of Waikato and the University of Otago reported having no Pasifika academics in the academic positions outlined (i.e., post-docs), with Lincoln University's only Pasifika representation at the professor/dean level which we will explore in our discussion on data collection further on.

\section{Qualitative}

The journeys outlined above by emerging Māori and Pasifika academics demonstrate that different pathways have been beneficial for emerging academics to gain professional experience; two of the people who shared stories now have permanent academic positions. However, they all describe a sense of insecurity about employment within the university labour system and also importantly highlight the excess labour expected of Māori and Pasifika academics that in some cases jeopardise their ability to gain permanent employment. Importantly, they all share the desire to obtain permanent work in the academy and, given the opportunity, would provide much needed Māori and Pasifika labour. These experiences contribute to the 'leaky pipeline'; however, the pipeline metaphor fails to capture these experiences. 


\section{A new model for thinking through pathways and pipelines}

The idea of a linear pipeline for Māori and Pasifika journeys into academic positions is not entirely appropriate. The data above indicate that the pipeline is broken, and that very few universities offer a clear and linear pathway for Māori and Pasifika into the most senior roles at universities. Our qualitative data also indicate that the metaphor of the pipeline fails to capture the complex nature of Māori and Pasifika academic journeys, ignoring that excess labour and precarity contribute to creating leaks in the pipeline. We present a metaphor that gives Pacific people the agency that the pipeline lacks while also acknowledging the systemic barriers that have been identified in this present paper and in previous research. In order to do this, we shift from linear progression and assumptions located in the pipeline metaphor to a navigational metaphor that enables multiple pathways and acknowledges systemic issues.

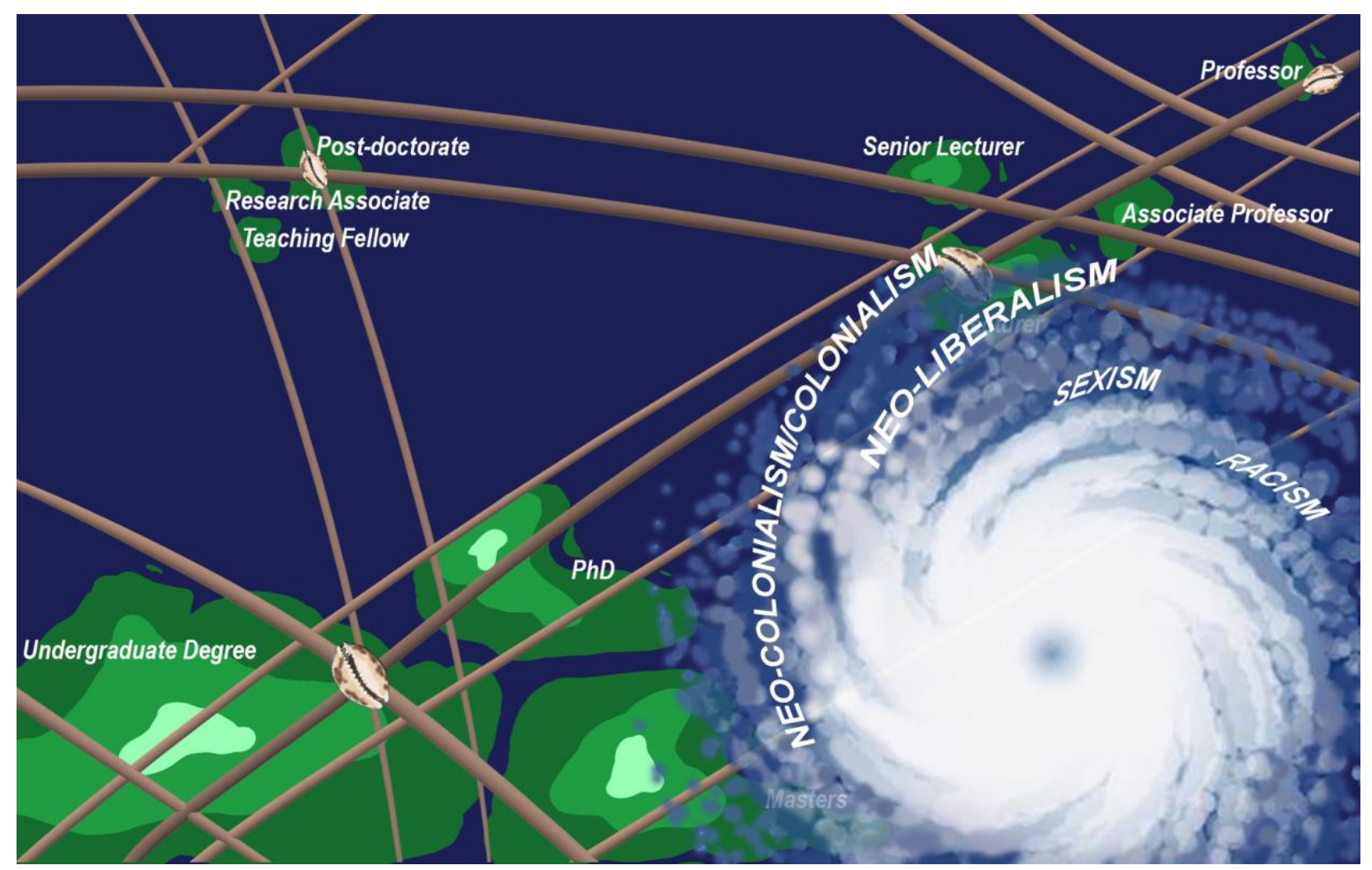

Figure 4. Pacific Navigation of Academic Pathways

Pacific peoples have long been scientists. Our ancestors navigated the world's largest ocean intentionally and repetitively (Howe, 2006; Jolly, 2007). We read the stars, watched the birds, and listened to the ocean as we navigated to the next island and beyond to the horizon. Those of us in the academy continue this tradition of looking to the horizon and imagining the next island and what we will need to understand and do in order to reach it. Figure 4 presents this navigational metaphor within the context of journeys into permanent employment within the university and navigating from PhD to professor. Building on Naepi's (2018) work that used navigation as a metaphor for Pasifika women working within the academy, we ask what possible islands are there for us to rest at, what storms will slow our progress, who and what are our 
drua/vaka/waka and how those who have gone before us help us in our journey? Naepi's (2018) original metaphor for higher education enables us to ensure that as Pacific peoples we have agency in our movements, recognise that there are many structural issues (i.e., racism, sexism, neoliberalism, capitalism etc.) that slow our progress, and also enable us to bring our communities with us.

\section{What do we already have in our drua/vaka/waka?}

Just like our ancestors we have in our own drua/vaka/waka our collective knowledge and experience to guide us in our journeying. This collective knowledge is shown through the use of the Marshallese navigation mapping (stick chart) (Howe, 2006). This enables us to visualise the ocean currents, wind patterns and wave swells (things that will speed us), as well as cowrie shells as island groups (different stops in our journeys). Each map is unique to the individual who creates it as we each carry different ancestors, family and community knowledge and experience. For this map the sticks (swells) represent the things that can speed us or support us on our journeys, our family, peers and mentors. Just like the Marshallese maps there are different swells present in this map. Backbone swells could be understood to be family and peers who provide constant support and can be seen here with the thicker sticks that cross each island. The thinner sticks could be weaker swells that are only detectable to knowledgeable people; these could be understood to be mentors. Not all of us are fortunate enough to have mentors who have travelled these journeys before and can identify the less known currents that could speed our journey. These can be seen in the thinner sticks that cross from the PhD to the 'pathways' island group, as mentors are able to explain and indicate how these pathway islands are beneficial and can be leveraged to permanent positions. The cowrie shell represents groups of islands. The Professor island intentionally has its own cowrie shell as it is an island that few Pacific people make it to, even though it is possible to imagine it as part of the academic positions' island group. It is our collective knowledge and experience that we carry in our drua/vaka/waka that speeds our navigation while we journey through the academy.

\section{What islands do we rest at?}

Island journeying did not occur in one sweep, it was a series of systematic journeys back and forth as our ancestors migrated in waves across the Pacific. Figure 4 envisions a journeying map where others have journeyed; we know the islands are there and we are continuing to journey in waves across the map. We rest at different islands and Figure 4 shows our possible resting places and each of the islands are proportional to the number of Pacific peoples who are currently found within those islands. Many of us currently rest and live in the large qualification island grouping (undergraduate degree, masters and PhD) and journeys within this island group are small as many have mapped this journey before us and remain within this space to mentor us on our own journeys between this island group.

Some of us will leave the qualifications grouping and journey to the smaller pathway group of islands (post-doctorate, research associate, teaching fellow). Even fewer of us will journey onto the academic positions' group of islands (senior lecturer, lecturer and associate professor) which are grouped together with professor further away given that so few Pacific people navigate to the island. Beyond that at the moment only 40 of us (McAllister et al., 2019; 
Naepi, 2019b) have journeyed to the Professor island; it is an island that few of us will see but not for a lack of trying; instead as outlined below there are weather systems that not just slow but potentially halt our journey to this island.

\section{What storms will slow our progress?}

It is possible to imagine systemic barriers in universities as storms that slow our progress (Naepi, 2018). Our map identifies neo-colonialism, colonialism, racism, sexism and neo-liberalism as a cyclone of barriers that slows us in our journeying which makes it difficult to see our mapping efforts, making it increasingly complex to navigate to islands. These weather systems need to be addressed if we want to see more Pacific peoples working in universities.

\section{What is beyond the horizon?}

It is also important for us to envision what lies beyond the horizon. The history of colonial education in Aotearoa and the Pacific was based on a system whereby education was specifically designed to provide Māori and Pacific with a vocational, as opposed to an academic, education (e.g., Hook, 2008; Simon, 1992). While some of us understand universities as being spaces that can be reformed to "embrace all learners, esteem all knowledges and serve all communities" (Naepi, 2019b, p. 230), we must also accept that there are others in our community who wish to work beyond the confines of academic institutions. As such, some members of our community may wish to travel beyond the islands identified and instead journey beyond the horizon locating islands that we have yet to navigate to.

\section{Recommendations}

Based on the findings from this present paper and previous research it is important not to underestimate the context that has led to the current situation for Māori and Pasifika in academia, that is, the structures and habits of universities may result in the exclusion of Māori and Pasifika bodies (McAllister et al., 2019; Naepi, 2017, 2019b). Whilst some are leading the way in attempting to address this such as AUT's Emerging Scholar programme (www.aut.ac.nz/about/ careers-at-aut/working-at-aut/maori-and-pacific-early-career-academic-programme), others still have a significant amount of work to do in their nurturing of emerging Māori and Pacific scholars before they will begin to address the problems evident in the data above. It is also important the programmes designed to nurture and provide opportunities for Māori and Pasifika scholars recognise and work against systemic issues outlined within the qualitative section such as excess labour and academic precarity. Universities need to move from excluding 'space invaders' (Puwar, 2004) to providing, creating, and maintaining islands that Māori and Pasifika academics can navigate to and beyond. There are few development opportunities between completing a doctorate and gaining permanent academic positions, and the increasingly competitive academic market means that Māori and Pasifika need opportunities to build experience such as postdoctoral fellowships and professional teaching fellowships. These development opportunities are particularly important for Māori and Pasifika who remain under-represented in academic 
positions, over-represented in precarious academic positions (McAllister et al., 2019; Naepi, $2019 \mathrm{~b}$ ) and to whom universities and the government have made specific commitments.

The context can also provide solutions. Currently, the TEC funds universities \$72.6 million for graduate degree completions with Māori and Pasifika completions resulting in universities receiving even more funding. However, the data above suggest that this money is not being reinvested into a system that creates opportunities for Māori and Pasifika to become academics. The TEC is committed to "Increasing research quality and capability" (TEC, 2019a, p. 11) and an education system that wishes to see Māori and Pasifika thrive. Therefore, it would seem that both of these mandates could be met by using $10 \%$ of that $\$ 72.6$ million to fund Māori and Pasifika post-doctoral positions nationally. On salaries of $\$ 80,000$ this would fund an extra 90 Māori and Pasifika post-doctoral positions each year. This would bring immense benefits to the universities themselves, supporting Māori and Pasifika research, providing role models and mentors for current Māori and Pasifika students and enabling the undertaking of research that could benefit our communities. Distributing degree completion funding is one example of a possible solution to a problem this paper sought to establish and provide a contextual solution, but future work is needed to address the many pathways raised in this paper.

\section{Data collection and dissemination}

In our previous work (McAllister et al., 2019; Naepi, 2019b) we have noted that data collection and dissemination of the ethnicity of the academic workforce must be improved and centralised across universities. This is an important way for universities to be transparent in their commitment to Te Tiriti o Waitangi and to diversity and how they are embodied in terms of numbers of Māori and Pasifika academics and the equitable academic career pathways created to better facilitate their journeys from undergraduate students to professors. How can the impact of a university's commitment to Te Tiriti and diversity be assessed if ethnicity data are not accurately collected and openly disseminated? How will universities be held accountable if such data are not publicly available? Further, universities must set specific targets and actions outlining how they plan to increase the recruitment, retention, and promotion of Māori and Pasifika staff. As well as this, universities must acknowledge how their systems make Māori and Pasifika staff 'space invaders' and work at dismantling these structures in order to make universities spaces and places where Pacific people can flourish.

There were several anomalies in the data obtained from the Ministry of Education that highlight some of the issues with monitoring at present. We are aware of several Māori and Pasifika academics who are not captured within the data, which calls into question how the Ministry of Education is ensuring universities are accountable in reporting accurate ethnicity data. For example, Lincoln University reported 150 post-doctoral fellows of unknown ethnicity in 2017, when in total they reported employing 365 academic staff. Lincoln University, therefore, reported having the third highest number of post-doctoral fellows in 2017, despite being the smallest university. It is important moving forward that universities have clear guidelines and parameters for defining pathway roles and reporting on them; this way we could track how many Māori and Pasifika are in professional teaching fellow and research associate roles as opposed to an overall 'other' classification. 


\section{Conclusion}

Clearly, there are institutional issues for Māori and Pasifika who choose to navigate into academic careers. If we use the traditional 'pipeline' metaphor, then it is clearly blocked for Māori and nonexistent for Pasifika. However, if we shift to a navigational metaphor, we can see that it is possible to create opportunities that support navigation, to locate islands that provide opportunities to build strength for the next phase of our journeys and to perhaps even imagine new possibilities beyond the horizon. Māori and Pasifika have shown they are prepared to journey, but what is now needed is government and institutional commitment to remove the storms that slow our progress and to support our journeying so that we can successfully navigate onwards to the horizon.

The paper is a wero, a direct challenge for universities and government to make meaningful structural changes that will transform the face of the academy in Aotearoa through the recruitment, retention, and promotion of Māori and Pasifika academics. Māori and Pasifika students need Māori and Pasifika academics who centre Māori and Pasifika ways of knowing. We want to acknowledge the hard work of those Māori and Pasifika academics who fight every day to create more spaces for Māori and Pasifika students and academics. However, the inequalities in the number of Māori and Pasifika academics must be addressed at an institutional and governmental level. This extra labour should not fall upon the already over-burdened shoulders of existing Māori and Pasifika academics and as such we need to consider how we are enabling and supporting emerging Māori and Pasifika to gain permanent employment in New Zealand universities.

\section{References}

Ahenakew, C., \& Naepi, S. (2015). The difficult task of turning walls into tables. In A. Macfarlane, M. Webber, \& S. Macfarlane (Eds.), Sociocultural theory: Implications for curricular across the sector (pp. 181-194). Christchurch: University of Canterbury Press.

Childress, H. (2019). The adjunct underclass: How America's colleges betrayed their faculty, their students, and their mission. Chicago: University of Chicago Press.

Education Counts. (2017). Research financing. Retrieved from https://www.educationcounts.govt.nz/statistics/tertiary-education/research

Finney, B., Howe, K. R., Irwin, G., Low, S., Neich, R., Salmond, A., ... \& Sale, O. (2007). Vaka Moana. Voyages of the ancestors: The discovery and the settlement of the Pacific. Honolulu: University of Hawaii Press.

Fradella, H. F. (2018). Supporting strategies for equity, diversity, and inclusion in higher education faculty hiring. In S. Gertz, B. Huang, \& L. Cyr (Eds.), Diversity and inclusion in higher education and societal contexts (pp. 119-151). Cham: Palgrave Macmillan.

Health Research Council. (2014). Health Research Council Pacific guidelines. Retrieved from New Zealand Health Research Council. Retrieved from http://www.hrc.govt.nz/sites/ default/files/Pacific\%20Health\%20Research\%20Guidelines\%202014.pdf

Hook, G. R. (2008). The political apology as a millennial phenomenon. MAl Review, 2(2). 1-13. 
Horta, H. (2009). Holding a post-doctoral position before becoming a faculty member: Does it bring benefits for the scholarly enterprise? Higher Education, 58(5), 689-721.

Jolly, M. (2007). Imagining Oceania: Indigenous and foreign representations of a sea of islands. The Contemporary Pacific, 19(2), 508-545.

Kandiko Howson, C. B., Coate, K., \& de St Croix, T. (2018). Mid-career academic women and the prestige economy. Higher Education Research \& Development, 37(3), 533-548.

Kidman, J., \& Chu, C. (2017). Scholar outsiders in the neoliberal university: Transgressive academic labour in the whitestream. New Zealand Journal of Educational Studies, 52(1), 7-19.

Kidman, J., \& Chu, C. (2019). 'We're not the hottest ethnicity': Pacific scholars and the cultural politics of New Zealand universities. Globalisation, Societies and Education, 17(4). 489499.

Māhina, H. O. (2008). From vale (ignorance) to 'ilo (knowledge) to poto (skill) the Tongan theory of ako (education): Theorising old problems anew. AlterNative: An International Journal of Indigenous Peoples, 4(1), 67-96.

Mallon, S., Māhina-Tuai, K. U., \& Salesa, D. I. (Eds.). (2012). Tangata o le moana: New Zealand and the people of the Pacific. Wellington: Te Papa Press.

McAllister, T., Kidman, J., Rowley, O., \& Theodore, R. (2019). Why isn't my professor Māori? A snapshot of the academic workforce of New Zealand. Mai, 8(2), 236-249.

Morley, L. (2005). Opportunity or exploitation? Women and quality assurance in higher education. Gender and Education, 17(4), 411-429.

Mountz, A., Bonds, A., Mansfield, B., Loyd, J., Hyndman, J., Walton-Roberts, M., ... \& Curran, W. (2015). For slow scholarship: A feminist politics of resistance through collective action in the neoliberal university. ACME: An International Journal for Critical Geographies, 14(4), 1235-1259.

Murray, M., Beban, A., \& Walters, V. (2018). Editorial. New Zealand Sociology, 33(2), 1-8.

Naepi, S., Stein, S., Ahenakew, C., \& Andreotti, V. (2017). A cartography of higher education attempts at inclusion and insights from Pasifika scholarship. In J. Major (Ed.), Global teaching: Southern perspectives on working with diversity. New York: Palgrave Macmillan.

Naepi, S. (2018). Beyond the dusky maiden: Pasifika women's experiences of eworking in higher education (PhD Diss.). University of British Columbia, Canada. Retrieved from http://hdl.handle.net/2429/66770

Naepi, S. (2019a). Pacific research methodologies. In G. Noblit (Ed.), Oxford research encyclopedia of education. New York: Oxford University Press. doi:10.1093/acrefore/9780190264093.013.ORE_EDU-00566.R1

Naepi, S. (2019b). Why isn't my professor Pasifika? A snapshot of the academic workforce of New Zealand. Mai, 8(2), 220-234.

Olssen, M., \& Peters, M. A. (2005). Neoliberalism, higher education and the knowledge economy: From the free market to knowledge capitalism. Journal of Education Policy, 20(3), 313-345.

Pihama, L., Lee-Morgan, J., Tiakiwai, S. J., Smith, L. T., Tauroa, T., Lonebear, D., Mahuika, R., \& Pihama-Seed, J. (2018). Te Tātua o Kahukura: A National project report to ko Aotearoa. 
Retrieved from Ako Aotearoa. https://ako.ac.nz/assets/Knowledge-centre/NPF-15009-He-Tatau-o-Kahukura/c89aadd7c5/REPORT-Te-Tatua-o-Kahukura.pdf

Puwar, N. (2004). Space invaders: Race, gender and bodies out of place. Oxford: Berg. Roper, B. (2018). Neoliberalism's war on New Zealand universities. New Zealand Sociology, 33(2), 9-39.

Sethna, B. N. (2011). Minorities in higher education: A pipeline problem? Research in Higher Education Journal, 13, 1-11.

Simon, J. (1992). European style schooling for Maori: The first century. Access, 11(2), 31-43.

Stringer, R., Smith, D., Spronken-Smith, R., \& WIlson, C. (2018). "My entire career has been fixed term": Gender and precarious academic employment at a New Zealand university. New Zealand Sociology, 33(2), 169-201.

Suaalii-Sauni, T. M. (2008). Critiquing Pasifika education at university. AlterNative: An International Journal of Indigenous Peoples, 4(1), 14-23.

Tertiary Education Commission. (2016). Performance Based Research Fund (PBRF) user manual. Retrieved from https://www.tec.govt.nz/assets/Forms-templates-andguides/8844b9fea9/PBRF-user-manual-November-2016-2.pdf

Tertiary Education Commission. (2019a). Performance-Based Research Fund. Retrieved from https://www.tec.govt.nz/funding/funding-and-performance/funding/fundfinder/performance-based-research-fund/

Tertiary Education Commission. (2019b). Performance-Based Research Fund (PBRF) 2018 Quality evaluation interim results. Retrieved from https://www.tec.govt.nz/assets/ Publications-and-others/f03baeafb7/PBRF-2018-Quality-Evaluation-FAQs.pdf

Thaman, K. H. (2003). Decolonizing Pacific studies: Indigenous perspectives, knowledge, and wisdom in higher education. The Contemporary Pacific, 15(1), 1-17.

Universities New Zealand. (2019). Building Māori and Pasifika success. Retrieved from https://www.universitiesnz.ac.nz/sector-research/building-ma\%CC\%84ori-andpasifika-success

Van Anders, S. M. (2004). Why the academic pipeline leaks: Fewer men than women perceive barriers to becoming professors. Sex Roles, 51(9-10), 511-521.

White, K., Carvalho, T., \& Riordan, S. (2011). Gender, power and managerialism in universities. Journal of Higher Education Policy and Management, 33(2), 179-188.

Ysseldyk, R., Greenaway, K. H., Hassinger, E., Zutrauen, S., Lintz, J., Bhatia, M., ... \& Tai, V. (2019). A leak in the academic pipeline: Identity and health among postdoctoral women. Frontiers in Psychology, 10, 1297.

Zusi, K. (2016). Breaking out of the academic pipeline. Cell, 165(7), 1557-1559.

Acknowledgement: We would like to acknowledge Professor Airini for her support of this paper.

\section{Biographical note:}

The research team behind this paper is made up of emerging and established Māori and Pasifika academics from across various universities. We are a cross-disciplinary team that includes education, sociology, psychology, fine arts, behavioural ecology, evolutionary biology, social and biological sciences, criminology, Pacific studies, Māori health, and international studies. Corresponding author: Sereana Naepi is.naepi@auckland.ac.nz 